DOI: $10.2478 /$ v.10169-012-0023-y

\title{
EFFECT OF NANO SILICA ON MECHANICAL PROPERTIES AND DURABILITY OF NORMAL STRENGTH CONCRETE
}

\author{
S. GOPINATH ${ }^{1}$, P.CH. MOULI ${ }^{3}$, A.R. MURTHY ${ }^{1}$, N.R. IYER ${ }^{2}$, S. MAHESWARAN ${ }^{1}$
}

\begin{abstract}
Nano technology is an emerging field of interest for civil engineering application. Among the nano materials presently used in concrete, nano-silica possess more pozzolanic nature. It has the capability to react with the free lime during the cement hydration and forms additional C-S-H gel giving strength, impermeability and durability to concrete. Present paper investigates the effects of addition of nano silica in normal strength concrete. Three types of nano-silica in the form of nano suspension having different amount of silica content have been investigated. Mix design has been carried out by using particle packing method. X-Ray diffraction (XRD) analysis has been carried out to find the chemical composition of control concrete and nano modified concrete. Further, experimental investigations have been carried out to characterize the mechanical behaviour in compression, tension and flexure. It has been observed that the addition of nano-silica in normal strength concrete increased the compressive strength and decreased the spilt tensile strength and flexural strength. Also, Rapid chloride permeability test (RCPT) has been conducted to know the chloride permeability of control concrete, nano modified concrete, and nano coated concrete. It has been observed that the chloride permeability is less for nano coated concrete.
\end{abstract}

Key words: Nano-silica, Nano modified concrete, XRD, Compressive Strength, Flexural Strength; RCPT, Cost Analysis.

\section{INTRODUCTION}

Nanotechnology is the engineering at nano-scale to produce materials with unique properties that cannot be achieved using traditional materials. For heterogenous composite such as concrete, addition of nano particle makes it an ideal candidate for the application of nanotechnology. The mechanical behaviour of concrete depends on the phenonena that occur at micro or nano scale. Hydrated cement paste which is the binder in concrete is formed by a chemical reaction with water and has structure on scales that

\footnotetext{
${ }^{1}$ Scientist, CSIR-SERC, Chennai CSIR - Structural Engineering Research Centre, CSIR Campus, Taramani, Chennai-600113, India, Fax: 91-44-22541508 e-mail: smithag@ serc.res.in, smithagopinath13@yahoo.com

${ }^{2}$ Director, CSIR-SERC, Chennai CSIR - Structural Engineering Research Centre, CSIR Campus, Taramani, Chennai-600113, India, Fax: 91-44-22541508

3 Project student, CSIR-SERC, Chennai CSIR - Structural Engineering Research Centre, CSIR Campus, Taramani, Chennai-600113, India, Fax: 91-44-22541508
} 
range from nanometers to millimetres. As a result, its structure can be modified and the hydration reactions can be controlled and altered. Nanoscale reinforcing materials can be readily introduced into the cement matrix. High performance concrete which uses supplementary cementing materials such as silica fume, blast furnace slag and fly ash also offer vast opportunities to apply nanotechnology.

Physical properties of concrete, particularly strength and permeability significantly depend on its pore structure. Ultra fine particles of nano silica fill the voids of C-S-H structure and provide more homogenous distribution of hydrated products. This effect of nano silica enhances the durability of cement composites as well as the strength. To study on the chloride permeability WEE et al.[1] conducted RCPT on a concrete mix with and without silica fume. The results indicated that there is a need to consider the volume fraction of the aggregate in the mix. Also, the research reported about the RCPT of concrete containing nano silica is scanty and there is a vast scope for such investigations. The charcatreisation studies reported by SHIH et al.[2] on the effect of nano silica in portaland cement composite opened up a considerable scope for reaserch in this direction.

Jo et al.[3] studied on the properties of cement mortar with nano-silica and found that nano-scale silica behaves not only as a filler to improve microstructure, but also as an activator to promote pozzolanic reaction. In the studies reported by LiN et al [4], it was shown that nano-silica could help to produce hydration crystals, which implies that the addition of nano-silica to mortar can improve the influence of sludge/fly ash on the development of the early strength of the mortar. Influence of nano-silica on different properties of cement mortar was investigated by SADRMOMTAZI et al.[5] in comparison with silica fume (SF), which is well-known active pozzolan. SENFF et al.[6] investigated on effect of nano-silica on rheology and fresh properties of cement pastes and mortars. Based on the studies it was observed that the addition of nano silica decreased spread and setting time compared to the samples without nano silica. X-ray diffraction studies showed the presence of early formation of calcium hydroxide compared to the samples without nano silica.

Givi et al.[7] investigated the size effects of $\mathrm{SiO}_{2}$ nano-particles on compressive, flexural and tensile strength of binary blended concrete. $\mathrm{SiO}_{2}$ nano-particles with two different sizes of 15 and $80 \mathrm{~nm}$ were used as a partial cement replacement by $0.5,1.0$, 1.5 and $2.0 \%$. It was concluded that concrete specimens containing $\mathrm{SiO}_{2}$ particles with average diameter of $15 \mathrm{~nm}$ were harder than those containing $80 \mathrm{~nm}$ of $\mathrm{SiO}_{2}$ particles at the initial days of curing. But this condition was altered at 90days of curing

In the present study nano silica gel is used to modify the micro structure of normal strength concrete. Mix design has been carried out using particle packing method. $\mathrm{X}$-Ray diffraction analysis (XRD) has been carried out to find the chemical composition of control concrete and nano modified concrete. Experimental investigations have been carried out to characterize the mechanical behaviour of nano modified concrete in compression, tension and flexure. RCPT hase been carried out to investigate the 
chloride permeability of normal strength concrete, nano modified concrete and nano coated concrete.

\section{Properties OF NANO-SIO 2}

In this study, three different types of suspended nano silica gel containing different percentages of active nano silica with $99.99 \%$ pure $\mathrm{SiO}_{2}$ is used. The nomenclature followed for different nano silica gel is given in Table 1. Specific gravity of each material varies from 1.08 to 1.32. Particle size of nano Silica varies between 5-40 nm. The $\mathrm{pH}$ of the solutions is between 9.3 and 10.4. The properties of different nano silica provided by the manufacturer are given in Table 1 .

Table 1

Properties of nano-silica.

\begin{tabular}{|c|c|c|c|}
\hline $\begin{array}{c}\text { Notation for Nano } \\
\text { Silica Gel }\end{array}$ & XLP & XTX & XFX \\
\hline $\begin{array}{c}\text { Active nano } \\
\text { content (\%wt/wt) }\end{array}$ & $14.0-16.0$ & $30.0-32.0$ & $40.0-41.50$ \\
\hline $\mathrm{pH}$ & $9.3-9.6$ & $9.0-10.0$ & $9.4-10.4$ \\
\hline Specific gravity & $1.08-1.11$ & $1.20-1.22$ & $1.30-1.32$ \\
\hline
\end{tabular}

\section{Mix DESIGN FOR NANO CONCRETE}

Particle packing is one of the mix design methods, which leads to a better and cost effective concrete. The main principle behind this concept is the minimization of void content by optimized packing of concrete ingredients. This will lead to the lowest cement consumption, porosity, and shrinkage and thus the concrete with the highest performance can be achieved. This concept was used in mix design of high performance cementitious mixes (Wang et al.[8], Domone and Wen [9]).

In the present study, particle packing method has been used for mix design of M30 grade of normal strength concrete and nano modified concrete (Fig. 1 and Fig. 2) to optimize the mix design The particle size distribution (PSD) of the sand and gravel is determined by sieve analysis.

From Fig. 2, it is observed that the effect of nano material in filling can't be depicted correctly using the particle packing method. To know the optimum quantity of nano material, more trial experiments have to be carried out. In the present study, trial experiments conducted are very limited and further investigations will be carried out in future to arrive at a precise mix deisgn procedure for nano modified concrete. However, the steps followed for addition of nano silica gel in normal concrete are given below. 


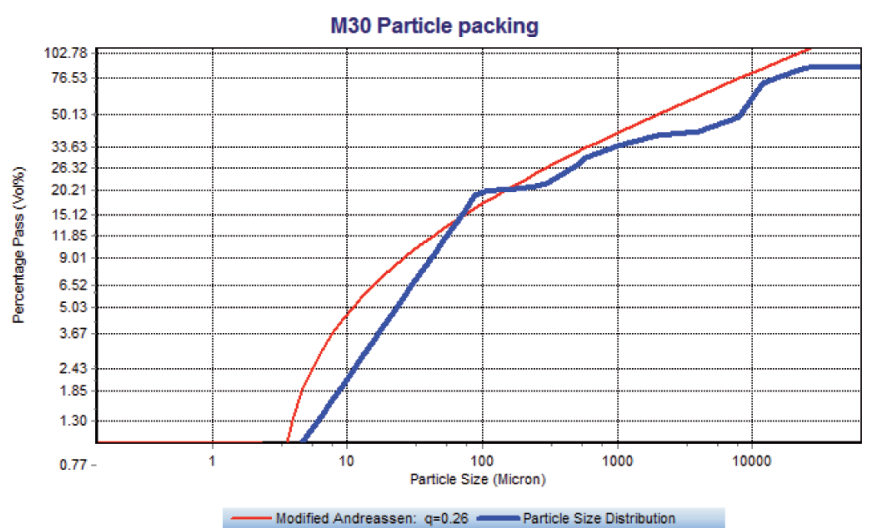

Fig. 1. Mix design for M30 concrete by particle packing method.

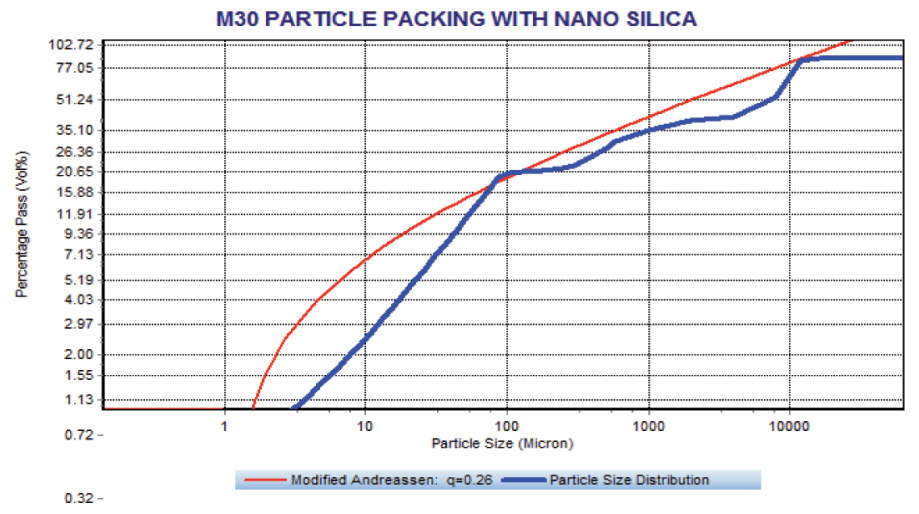

Fig. 2. Mix design for nano-concrete by particle packing method.

1. For pore filling nano silica has to be in solid form. Hence for calculation of silica content only solid nano silica is taken while remaining liquid gel is subtracted from water to be used in concrete.

2. Replaced solid nano silica by $1.5 \%$ and $3 \%$ of water.

3. Removed the solid nano silica (nS) content from cement and liquid gel from water for balancing mix as shown in Table 2 .

A condensed form of typical mix design is given in Tables $2 \& 3$.

\section{X-Ray Diffraction Analysis [XRD]}

XRD is a fast method to collect mineralogical information and this can subsequently be processed in different ways to obtain quantitative results in concrete construction. Dif- 
Example of $1.5 \%$ replacement of XLP type Nano Silica.

Table 2

\begin{tabular}{|c|c|c|c|}
\hline Components & Control & Effected 1.5\% & Balanced 1.5\% \\
\hline Cement (gm) & 1000 & 1000 & $993.25(1000-6.75)$ \\
\hline Sand $(\mathrm{gm})$ & 1270 & 1270 & 1270 \\
\hline Gravel $(\mathrm{gm})$ & 2180 & 2180 & 2180 \\
\hline NS Solution (ml) & - & $\begin{array}{c}45(6.75 \mathrm{nS}+ \\
38.25 \text { water })\end{array}$ & $\begin{array}{c}45(6.75 \mathrm{nS}+ \\
38.25 \text { water })\end{array}$ \\
\hline Water $(\mathrm{ml})$ & 450 & 411.75 & 411.75 \\
\hline
\end{tabular}

Table 3

The ratio of different ingredients of concrete.

\begin{tabular}{|c|c|c|c|c|c|c|c|}
\hline MIX ID & CONTROL & XLP 1.5 & XLP 3 & XTX 1.5 & XTX 3 & XFX 1.5 & XFX 3 \\
\hline Sand/Cement ratio & 1.27 & 1.27 & 1.27 & 1.27 & 1.27 & 1.27 & 1.27 \\
\hline $\begin{array}{c}\text { Aggregate } \\
\text { /Cement ratio }\end{array}$ & 2.18 & 2.18 & 2.18 & 2.18 & 2.18 & 2.18 & 2.18 \\
\hline \% Nano silica added & 0 & 1.5 & 3 & 1.5 & 3 & 1.5 & 3 \\
\hline Water/Cement ratio & 0.45 & 0.412 & 0.374 & 0.435 & 0.42 & 0.44 & 0.434 \\
\hline
\end{tabular}

fraction experiments can be performed on small angle crystals and fine homogeneous powder samples showing anisotropic distribution of crystal orientation.

In the present study, in order to obtain concrete powder, samples were taken from cubes of control concrete and nano modified concrete. The samples were finely ground using mortar and pestle, and then sieved through 25 micron sieve. Brucker's D2 PHASER XRD system, equipped with the 1-dimensional LYNXEYE detector is used for the study. It employs Cu radiation $(30 \mathrm{kV}, 10 \mathrm{~mA})$ and uses Nickel filters. It can perform continuous scans from 10 to $70^{\circ}$ 2Theta,in step width of $0.02^{\circ}$, counting time $0.5 \mathrm{sec}$ per step. The total scan time is about 25 mins- 45 mins. The formation of various mineral compound phases have been identified by XRD for control concrete as shown in the Fig. 3. The sample from XFX has been chosen for the XRD study, since it has shown considerable improved strength on the 28th day concrete and the same nano modified concrete of XFX 1.5 is as shown in the Fig. 4.

From the intensity mapping of the above charts, it shows the clear indication of the formation of an additional $\mathrm{C}_{3} \mathrm{~S}$ in the nano modified materials when compared to the control mix, that could led to the formation of $\mathrm{C}-\mathrm{S}-\mathrm{H}$ gel, which is a strength giving phase and betterment of packing in concrete. Moreover, it is also seen that the intensity reduction of $\mathrm{CaOH}_{2}$ phases in the nano modified concrete compared to the control gives the indication of early consumption of the calcium hydroxide for the formation of $\mathrm{C}-\mathrm{S}-\mathrm{H}$ in the presence of $\mathrm{C}_{3} \mathrm{~S}$. 


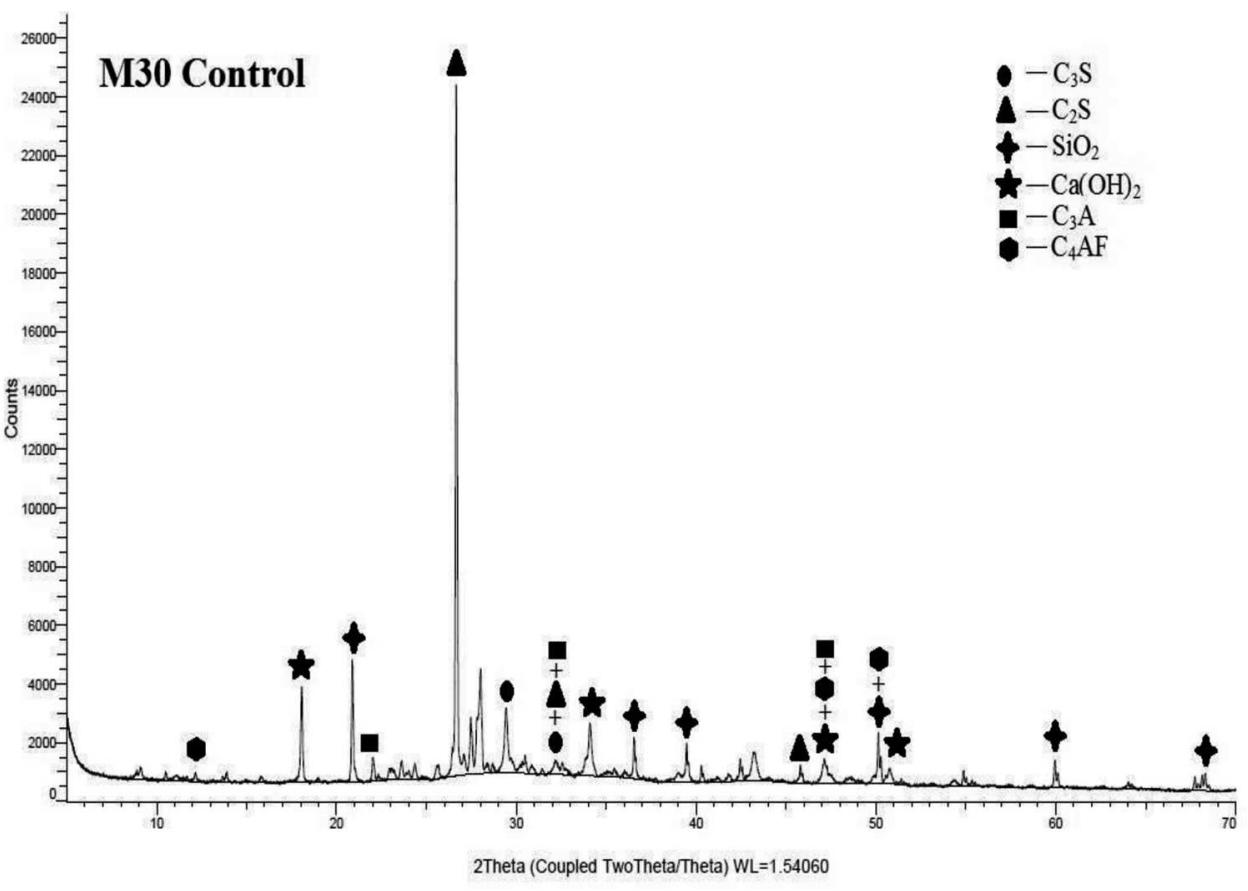

Fig. 3. XRD of M30 control concrete.

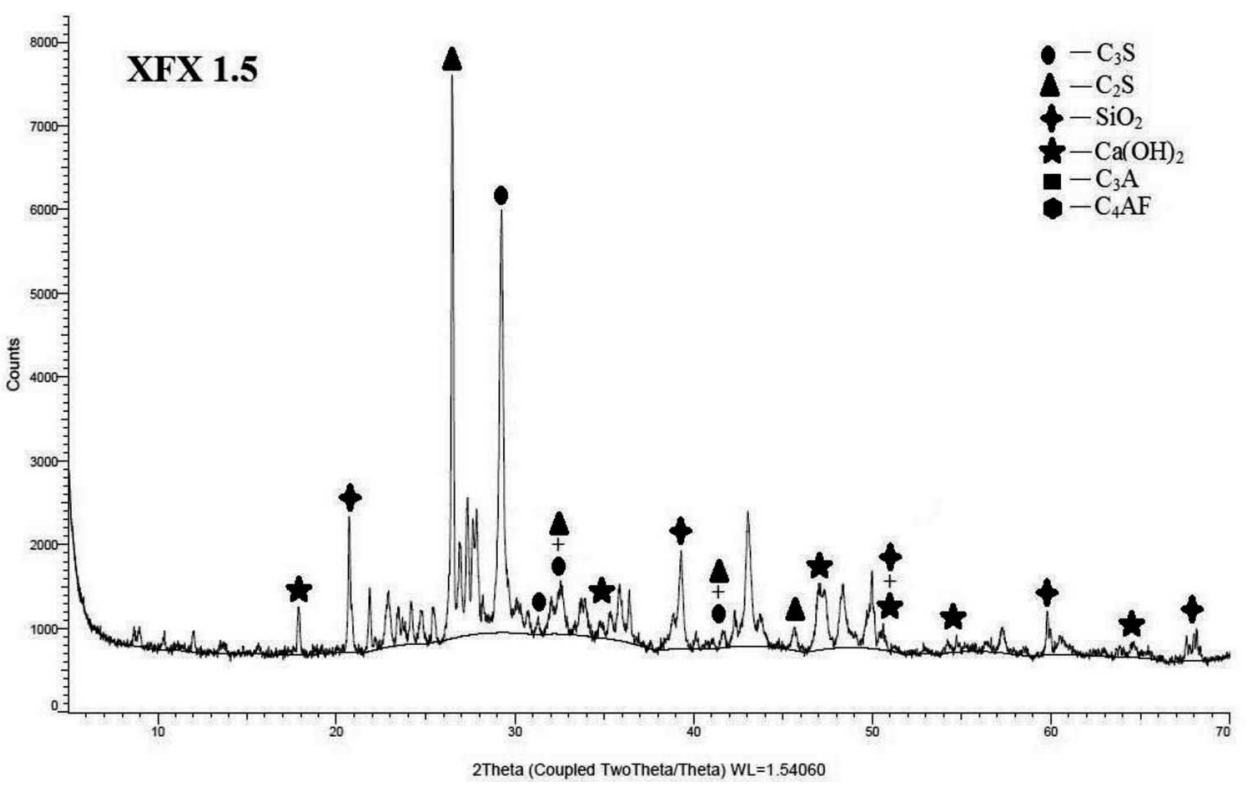

Fig. 4. XRD of Nano modified concrete containing XFX1.5. 


\section{Mechanical Characterization}

Mechanical properties such as compressive strength, split tensile strength and flexural strength have been evaluated by conducting experimental investigations on nano modified concrete.

\subsection{COMPREsSive STRENGTH}

To determine the compresssive strength of concrete, the cube specimen of size $15 \times 15 \times 15$ $\mathrm{cm}$ have been cast. The test cube specimens are made as close as practicable after mixing in order to ensure a symmetrical distribution of the concrete with in the mould. Proper compaction is done during casting. The test specimens are stored in place having at least $90 \%$ relative humidity at a room tempereature for 24 hours. After this period the specimens are removed from the moulds and immediately submerged in clean fresh water and kept there till $28^{\text {th }}$ day testing.

The compression test has been carried out on 100t UTM under load control. Compressive strength of control concrete and nano modified concrete for 3, 14, 28 and 56 days is shown in Table 4. It is observed that the addition of nano-silica to concrete increased the compressive strength of concrete to 6 to $13 \%$ compared to control concrete.

Table 4

Compressive strength for different concrete mix.

\begin{tabular}{|c|c|c|c|c|c|c|c|c|c|c|}
\hline \multirow{3}{*}{ S.NO } & \multirow{2}{*}{$\begin{array}{c}\text { MATERIAL } \\
\text { CODE }\end{array}$} & \multirow{2}{*}{$\begin{array}{c}\text { \% } \\
\text { ADDED }\end{array}$} & \multicolumn{4}{|c|}{$\begin{array}{c}\text { COMPRESSIVE } \\
\text { STRENGTH(MPa) }\end{array}$} & \multicolumn{3}{c|}{$\begin{array}{c}\text { \% INCREASE IN } \\
\text { COMPRESIVE STRENGTH } \\
\text { wrt CONTROL }\end{array}$} \\
\cline { 4 - 11 } & & 3 & $\begin{array}{c}14 \\
\text { DAY }\end{array}$ & $\begin{array}{c}28 \\
\text { DAY }\end{array}$ & $\begin{array}{c}56 \\
\text { DAY }\end{array}$ & $\begin{array}{c}3 \\
\text { DAY }\end{array}$ & $\begin{array}{c}14 \\
\text { DAY }\end{array}$ & $\begin{array}{c}28 \\
\text { DAY }\end{array}$ & $\begin{array}{c}56 \\
\text { DAY }\end{array}$ & DAY \\
\hline 1 & CONTROL & 0 & 34.01 & 44.61 & 49 & 53.5 & & & & \\
\hline 2 & XLP-1.5 & 1.5 & 33.61 & 46.98 & 54.45 & 58.8 & -1.18 & 5.31 & 11.12 & 9.91 \\
\hline 3 & XLP-3 & 3 & 38.1 & 50.34 & 52.45 & 59.4 & 13.36 & 12.84 & 7.04 & 11.03 \\
\hline 4 & XTX-1.5 & 1.5 & 31.87 & 45.49 & 53.67 & 56.7 & -16.35 & 1.97 & 9.53 & 5.98 \\
\hline 5 & XTX-3 & 3 & 34.88 & 48.29 & 50.13 & 56.4 & 9.44 & 8.25 & 2.31 & 5.42 \\
\hline 6 & XFX-1.5 & 1.5 & 36.49 & 49.13 & 54.52 & 58.5 & 4.62 & 10.13 & 11.27 & 9.35 \\
\hline 7 & XFX-3 & 3 & 37.03 & 49.47 & 55.14 & 58.9 & 1.48 & 10.89 & 12.53 & 10.1 \\
\hline
\end{tabular}

\subsubsection{Observations}

From the investigations, it can be noted that concretes with $1.5 \%$ of nano silica has got less increase in $3^{\text {rd }}$ day strength compared to concrete containing $3 \%$ nano silica. But there is a comparable increase in at $28^{\text {th }}$ day strength for concrete containing $1.5 \%$ nano silica as given in Table 4. Among the three types of nano silica used, XFX-3 gave maximum increase in compressive strength. 


\subsection{Split Tension}

The tensile strength of concrete is most often evaluated using a split cylinder test, in which a cylindrical specimen is placed on its side and loaded in diametrical compression, so as to induce transverse tension. In the present study, cylinders of $150 \mathrm{~mm}$ diameter $\times 300 \mathrm{~mm}$ height has been used for conducting split tensile test. The tensile strength obtained for different concretes is presented in Table 5. It is observed that there is a reduction in tensile strength for concretes containing nano silica which needs further investigations. One reason for this may be due to the defects generated in dispersion of nano particles that cause weak zones in concrete.

Table 5

Split tensile strength.

\begin{tabular}{|c|c|c|c|}
\hline \multirow{2}{*}{ S.NO } & \multirow{2}{*}{ Material code } & \multirow{2}{*}{ \% Nano silica added } & Split tensile strength (MPa) \\
\cline { 4 - 4 } & & & 28 Day \\
\hline 1 & CONTROL & 0 & 4.2 \\
\hline 2 & XLP-1.5 & 1.5 & 3.89 \\
\hline 3 & XLP-3 & 3 & 4 \\
\hline 4 & XTX-1.5 & 1.5 & 3.83 \\
\hline 5 & XTX-3 & 3 & 4.06 \\
\hline 6 & XFX-1.5 & 1.5 & 3.87 \\
\hline 7 & XFX-3 & 3 & 3.79 \\
\hline
\end{tabular}

Results in Table 5 shows that split tensile strength of nano concrete is less compared to that of control concrete. The split tensile strength of $1.5 \%$ replacement is $7 \%$ to $9 \%$ lesser than control concrete but for 3\% replacement of XLP-3 is $4.8 \%$, XTX-3 is 3.3\%, $\mathrm{XFX}-3$ is $9.8 \%$ lesser than the control concrete. Upon relating the compressive strength to split tensile strength, it is observed that for nano concretes the split tensile strength decreases with increase in compressive strength. For XFX-3 compressive strength is $12.5 \%$ higher than control concrete but split tensile strength is $9.8 \%$ lower than control concrete. For XTX-3 compressive strength is $2.3 \%$ higher than control concrete but split tensile strength is $3.3 \%$ lower than control concrete. This clearly gives an idea how the split tensile strength is varying with increase in compressive strength irrespective of percentage of nano silica added.

\subsection{Flexural Strength}

In the present study, central point loading has been applied to find out the flexural strength of beams. Five beams of size $650 \times 130 \times 50 \mathrm{~mm}$ have been cast in which 2 beams are control, and other 3 beams are containing XFX 3\%. The bearing surfaces of the supporting and loading rollers are wiped clean, and are made to contact with the rollers. The axis of specimen is carefully aligned with the axis of the loading device. 
The load is applied gradually until the specimen fails, and the maximum load applied to the specimen during the test is recorded. The flexural strength values are given in Table 6. From the Table 6, it is noticed that flexural strength for concrete XFX 3\% is $5 \%$ lower than the control concrete. The visible appearance of the fractured faces of concrete and type of failure is shown in Fig. 5.

Table 6

Flexural strength of different concrete mix.

\begin{tabular}{|c|c|c|c|c|}
\hline \multirow{2}{*}{ S.NO } & \multirow{2}{*}{ MATERIAL CODE } & \multicolumn{3}{|c|}{} \\
\cline { 3 - 4 } & Control & 0 & $\begin{array}{c}\text { Flexural } \\
\text { Strength(MPa) } \\
28 \text { DAY }\end{array}$ & $\begin{array}{c}\text { Average Flexural } \\
\text { Strength } \\
\text { (MPa) }\end{array}$ \\
\hline 1 & Control & 0 & 4.62 & 4.985 \\
\hline 2 & XFX 3\% & 3 & 4.35 & \multirow{2}{*}{4.74} \\
\hline 3 & XFX 3\% & 3 & 4.98 & \\
\hline 4 & XFX 3\% & 3 & 4.26 & \\
\hline 5 & & & & \\
\hline
\end{tabular}

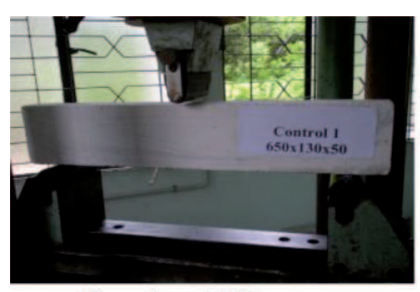

Experimental Setup

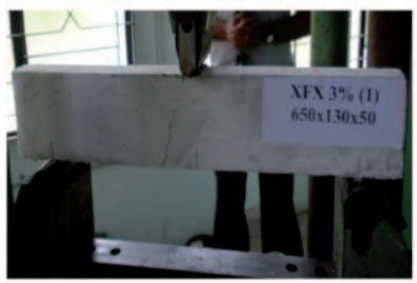

Crack pattren for sample 3 XFX $3 \%$

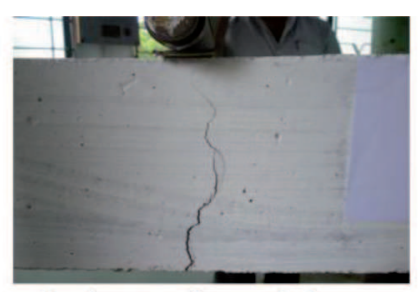

Crack pattren for sample 1

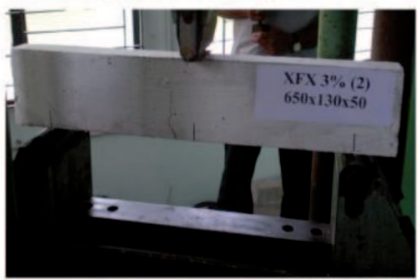

Crack pattren for sample 4 XFX $3 \%$

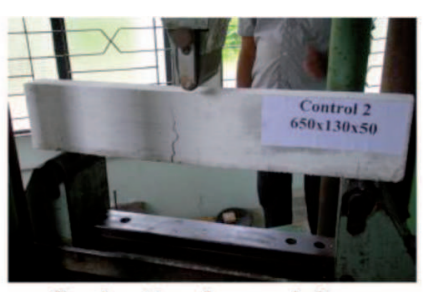

Crack pattren for sample 2

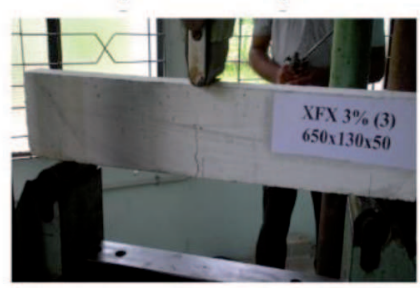

Crack pattren for sample 5 XFX $3 \%$

Fig. 5. Failure specimens in flexure.

\section{Rapid Chloride Permeability Test}

A concrete is said to be durable if it withstands the conditions for which it has been designed, without deterioration, over a period of years. Chlorides can be introduced into concrete by coming into contact with environments containing chlorides, such as seawater or deicing salts. In the present study, RCPT has been performed as per 
ASTM-C-1202 to determine the electrical conductance and chloride permeability of three different types of concrete viz., control concrete, nano modified concrete and nano coated concrete. The nano coated concrete mentioned in this study is prepared by immersing control concrete and nano-concrete in nano Silica solution for 12 hours.

The RCPT is performed by monitoring the amount of electrical current that passes through a sample of $50 \mathrm{~mm}$ thick $\times 100 \mathrm{~mm}$ diameter for 6 hours. This sample is typically cut as a slice of a core or cylinder. A voltage of $60 \mathrm{~V} \mathrm{DC}$ is maintained across the ends of the sample throughout the test. One lead is immersed in a sodium chloride $(\mathrm{NaCl})$ solution $(0.5 \mathrm{~N})$ and the other in a sodium hydroxide $(\mathrm{NaOH})$ solution $(0.3 \mathrm{~N})$. The RCPT test set-up is shown in Fig. 6. From the current readings, total charge passed is calculated using the Eqn(1). The RCPT results are given in Table 7.

Table 7

Rapid chloride permeability test results.

\begin{tabular}{|c|c|c|c|c|}
\hline & \multicolumn{2}{|c|}{ Charge passed in columbs } & \multicolumn{2}{c|}{$\begin{array}{c}\text { Increase in charge } \\
\text { passed wrt control concrete }\end{array}$} \\
\hline MIX & Concrete & Nano coated concrete & Concrete & Nano coated concrete \\
\hline Control & 2843 & 2864 & - & 0.7 \\
\hline XLP 1.5 & 3086 & 3029 & 8.6 & 6.5 \\
\hline XLP 3 & 3104 & 3052 & 9.2 & 7.3 \\
\hline XFX 1.5 & 2662 & 2879 & -6.4 & 1.3 \\
\hline XFX 3 & 3177 & 2900 & 11.7 & 2 \\
\hline XTX 1.5 & 3038 & 2795 & 6.9 & 1.7 \\
\hline XTX 3 & 3576 & 3644 & 25.8 & 28.2 \\
\hline
\end{tabular}

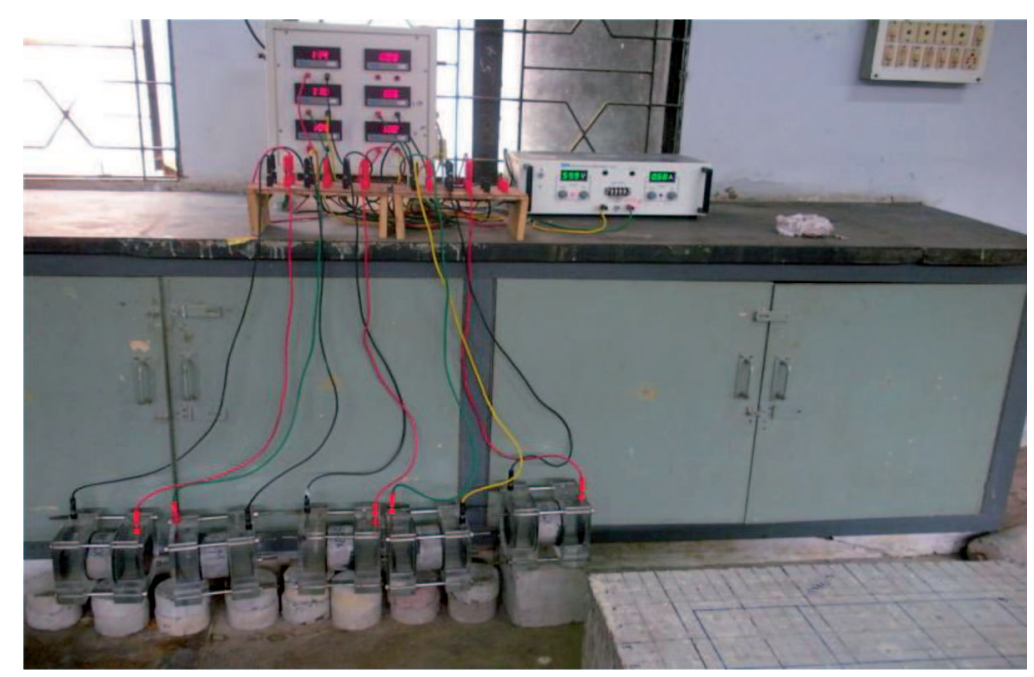

Fig. 6. RCPT Experimental Set up. 


$$
Q=900\left(I_{0}+I_{360}+2\left(I_{30}+I_{60}+\ldots \ldots \ldots+I_{300}+I_{330}\right)\right)
$$

where, $\mathrm{Q}$ - Charge passes (Coulomb), $\mathrm{I}_{0}$ - current (ampere) immediately after voltage is adapted, and $\mathrm{I}_{360}$ - current (ampere) at 360min after voltage is applied.

From Table 7, it can be observed that the chloride permeability for nano concrete is more compared to control concrete whereas it is less in the case of nano coated concrete. The present study gives an indication that nano silica can be applied as a coating material for concrete reducing the chloride penetration.

\section{Conclusions}

Investigations were carried out on nano modified concrete for evaluation of chemical composition, mechanical characterization and chloride permeability. The chemical composition of control concrete and nano modified concrete were determined by XRD analysis. From XRD analysis, it is observed that there is a reduction in amount of $\mathrm{Ca}(\mathrm{OH})_{2}$ for nano modified concrete indicating the formation of additional C-S-H gel. From mechanical characterization of compressive strength, it is observed that the compressive strength of concretes containing nano-silica is higher than that of the control concrete. Regarding tensile strength, it is observed that there is a decrease in the split tensile strength and flexural strength of nano modified concrete compared to control concrete. Chloride permeability has been assessed for control concrete, nano modified concrete and nano coated concrete using RCPT. It is observed that there is a reduction in the chloride permeability for nano coated concrete and hence nano silica can be applied as an external coating, leading towards durable concrete construction. Also, there is a scope for generalizing the mix design of concrete containing nano silica, for which more experiments have to be carried out.

\section{AKNOWLEDGEMENTS}

The authors acknowledge the cooperation and support provided by the staff of Advanced Materials Laboratory, Advanced Concrete Testing and Evaluation Laboratory and Structural Testing Laboratory, CSIR-SERC for carrying out experiments. Thanks are extended to Shri V. Ramesh kumar, Scientist and Ms. B. Bhuvaneswari, Quick Hire Fellow for fruitful discussions during the investigations. This paper is being published with the kind permission of the Director, CSIR-SERC, India.

\section{REFERENCES}

1. T.H. Wee, A.K. Suryavanshi, S.S. Tin, Influence of Aggregate Fraction in the Mix on the Reliability of the Rapid Chloride Permeability Test, Cement \& Concrete Composites, 21, 1, 59-72, 1999. 
2. J.Y. Sнiн, T.P. Сhang, T.C. Hsiao, Effect of nanosilica on characterization of Portland cement composite, Cement Concrete Research, 36, 697-706, 2006.

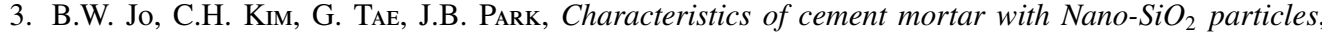
Construction and Building Materials, 21, 6, 1351-1355, 2007.

4. K.L. Lin, W.C. Chang, D.F. Lin, H.L. Luo, M.C. Tsai, Effects of Nano-SiO ${ }_{2}$ and different ash particle sizes on sludge ash-cement mortar, Journal of Environmental Management, 88, 4, 708-714, 2008.

5. A. SadrmomtaZi, Fasihi, F. Balalaei, A.K. Haghi, Investigation of mechanical and physical properties of mortars containing silica fume and $\mathrm{Nano}-\mathrm{SiO}_{2}$, The third International Conference on Concrete \& Development, 1153-1161, 2009.

6. L. SenfF, J.A. Labrincha, V.M. Ferreira, D. Hotza, W.L. Repette, Effect of nano-silica on rheology and fresh properties of cement pastes and mortars, Construction and Building Materials, 23, 7, 2487-2491, 2009.

7. A.N. Givi, S.A. Rashid, F.N.A. Aziz, M.A.M. SAlleh, Experimental investigation of the size effects of $\mathrm{SiO}_{2}$ nano-particles on the mechanical properties of binary blended, concrete Composites Part B: Engineering, 41, 8, 673-677, 2010.

8. A. Wang, C. Zhang, N. Zhang, Study of the influence of the particle size distribution on the properties of cement, Cement and Concrete Research, 29, 11, 685-695, 1997.

9. P. Domone, C.H. Wen, Testing of binders for high performance concrete, Cement and Concrete Research, 27, 8, 1141-1147, 1997.

Remarks on the paper should be sent to the Editorial Office

no later than March 30, 2013
Received August 8, 2012 revised version

November 15, 2012 